El gasto fiscal de la guerra contra los portadores de drogas ilícitas: una aproximación para Colombia

Isabel Gutiérrez y Santiago Tobón 
Lecturas de Economía, 91 (julio-diciembre 2019), pp. 79-116

\author{
Isabel Gutiérrezy Santiago Tobón
}

\title{
El gasto fiscal de la guerra contra los portadores de drogas ilícitas: una aproximación para Colombia
}

Resumen: Alrededor del mundo, los gobiernos dedican un gran volumen de recursos públicos al control del porte, fabricación y tráfico de drogas ilicitas. En general, estos costos son difíciles de observar, pues corresponden al costo de oportunidad de muchos funcionarios que intervienen en el proceso. En este artículo se estima, para el caso de Colombia, el costo esperado por captura para los delitos de porte, fabricación y tráfico de drogas ilícitas. Los resultados muestran que el costo esperado de una captura es de $\$ 11$ millones, por lo que el costo esperado asociado a las 984.106 capturas realizadas entre 2001 y 2015 es cercano a los \$10,6 billones. Además, se analizó si la persecución al tráfico internacional de drogas ilícitas, al crimen asociado al microtráfico en mercados locales o la disuasión a los consumidores justifican este esfuerzo fiscal. Se concluyó que ninguna de estas razones lo hace, y que más bien se relaciona con incompatibilidad de incentivos en las autoridades colombianas.

Palabras clave: sistema de justicia criminal; costos sociales; drogas ilícitas; gasto público; incentivos en la policía.

Clasificación JEL: H11, H56, K14, K42, P35.

\section{The fiscal expenditure of the war against possessors of illicit drugs: an approximation for Colombia}

\begin{abstract}
Around the world, governments spend enormous amounts of public funds in controlling possession, manufacturing and trafficking of illicit drugs. These costs are usually difficult to observe, as they correspond to the opportunity cost of many bureaucrats involved in the process. In this paper, we estimate the expected cost per arrest for possession, manufacturing or trafficking of illicit drugs for the case of Colombia. We find that the expected cost of an arrest is roughly COP\$11 million, hence the expected total cost associated with the 984,106 arrests carried out between 2001 and 2015 adds up to COP\$10.6 billion. Also, we analyse whether these expenditures are justified by the control of international drug trafficking, crime associated with drug dealing in local markets or drug abuse deterrence. We conclude that none of these reasons justify such fiscal expenditures; rather, these seem to be explained by an issue of incentive compatibility in Colombian authorities.
\end{abstract}

Keywords: criminal justice system; social costs; illicit drugs; public expenditure; police incentives.

JEL Classification: $H 11, H 56, K 14, K 42, P 35$.

Les dépenses fiscales de la guerre contre les détenteurs de drogues illicites : un rapprochement pour la Colombie

Résumé: Dans le monde entier, les gouvernements consacrent un volume important de ressources publiques au contrôle du transport, de la fabrication et du trafic de drogues illicites. En général, ces coûts sont difficiles à observer car ils correspondent au coût d'opportunité de nombreux fonctionnaires impliqués dans le processus. Dans cet article, on estime, dans le cas de Colombie, le coût prévu de la capture concernant la détention, la fabrication et le trafic de drogues illicites. Les résultats montrent que le coût prévu d'une capture est de COP\$11 millions. Par conséquent, le coût associé aux 984106 captures réalisées entre 2001 et 2015 avoisine les COP\$10,6 milliards. En outre, il a été analysé si la persécution du trafic international de drogues illicites, le crime associé au micro-trafic sur les marchés locaux ou la dissuasion des consommateurs justifiaient cet effort fiscal. Il en a été conclu qu'aucune de ces raisons ne le justifie et que cela est plutôt lié à l'incompatibilité des incitations offertes par les autorités colombiennes.

Mots clés: système de justice pénale; coûts sociaux; drogues illicites; dépenses publiques; incitations dans la police.

Classification JEL: H11, H56, K14, K42, P35. 


\title{
El gasto fiscal de la guerra contra los portadores de drogas ilícitas: una aproximación para Colombia
}

\author{
Isabel Gutiérrez $\mathbb{1}^{\mathrm{a}}$ y Santiago Tobón $\mathbb{1}^{\mathrm{b}}$
}

\begin{abstract}
-Introducción. -I. Ciclo criminal. - II. Los costos sociales de la persecución al delito de porte, fabricación y tráfico de estupefacientes. - III. Otros costos sociales asociados al consumo de drogas ilícitas. -Discusión.-Agradecimientos. -Referencias.
\end{abstract}

doi: 10.17533/udea.le.n91a03

Primera versión recibida el 13 de noviembre de 2018; versión final aceptada el 30 de enero de 2019

\section{Introducción}

Colombia dedica grandes esfuerzos a la persecución del delito de porte, fabricación y tráfico de estupefacientes, que se encuentra tipificado por el artículo 376 del Código Penal colombiano. En sus orígenes, este delito castigaba tanto a consumidores como a microtraficantes para el mercado local o traficantes internacionales; sin embargo, a lo largo de los años, las Cortes han creado una jurisprudencia que ha procurado un enfoque más humano para los consumidores y se analiza la problemática como un asunto de salud pública más que de seguridad ciudadana. En 1994, por ejemplo, la Corte Constitucional se declaró que el porte de la dosis mínima para consumo personal no debería implicar la judicialización de quienes la portan. ${ }^{1}$ El último de estos esfuerzos corresponde a la Corte Suprema de Justicia, que en 2016 señaló que los jueces deben eximir de responsabilidad penal a las personas

a Isabel Gutiérrez: investigadora, Universidad EAFIT, Colombia. Dirección postal: Carrera 49 No.7 Sur-50. Medellín, Colombia. Dirección electrónica: igutierr@eafit.edu.co. https:/ / orcid.org/0000-0001-8830-2297

b Santiago Tobón: investigador post-doctoral, Universidad de Chicago e Innovations for Poverty Action, Estados Unidos. Dirección postal: Calle 98 No. 22-64 Of 307 Bogotá, Colombia. Dirección electrónica: tobon@uchicago.edu. https://orcid.org/0000-0001-5274-6697

1 Corte Constitucional, Sentencia C-221 de 1994, magistrado ponente: Carlos Gaviria Díaz. 
Gutiérrez y Tobón: El gasto fiscal de la guerra contra los portadores de drogas ilícitas:...

que porten estupefacientes para el consumo personal, independientemente de las cantidades. ${ }^{2}$

No obstante, entre 2001 y 2015 se dieron cerca de un millón de capturas por el delito de porte, fabricación y tráfico de estupefacientes en Colombia y, en general, no es clara la diferenciación entre portadores y consumidores. Adicionalmente, el Gobierno de Colombia ha implementado recientemente medidas que facultan e incentivan a la policía para decomisar cualquier cantidad de droga que sea portada por un ciudadano, sin importar si se tiene más o menos de la dosis mínima. ${ }^{3}$ Los efectos de esta medida aún no son claros, pero presumiblemente aumentarán el número de capturas asociadas al consumo (especialmente cuando las dosis portadas sean mayores a la dosis mínima). Con esta ambigüedad se desarrolla este estudio, en el cual se estiman los costos asociados a estas capturas y se analiza si realmente se encuentran relacionadas con el microtráfico o el tráfico internacional o, si por el contrario, se asocian principalmente a la persecución del consumo de drogas ilícitas. ${ }^{4}$

Para la estimación de los costos nos basamos en el ciclo criminal del delito de porte, fabricación y tráfico de estupefacientes. En particular, se estudian las etapas de este ciclo, según lo establece el derecho penal, y se utilizan datos de la Policía, la Fiscalía, el Ministerio de Justicia y del Derecho y del Instituto Nacional Penitenciario y Carcelario (INPEC) para construir probabilidades condicionales de tomar las diversas rutas del ciclo. Por ejemplo, un porcentaje de las capturas continúa con una imputación y otro no. Entre los casos en los que procede la imputación, algunos casos precluyen y otros no; a su vez, entre los casos que no precluyen, en algunos se da la aceptación de cargos y celebración de acuerdos con la Fiscalía, mientras que en otros se continúa hasta la finalización del juicio oral. Adicionalmente, se estima el

2 Corte Suprema de Justicia, Radicado 41760 de 2016, magistrado ponente: Eugenio Fernández Carlier.

3 Para un ejemplo, véase la información de la Presidencia de la República en: https://id.presidencia.gov.co/Paginas/prensa/2018/181001-Gobierno-Nacional-firmadecreto-reglamentario- para-combatir-el-microtrafico-de-drogas-en-espacios-publicos.aspx

4 En la práctica, no es posible hacer una diferenciación a priori, en tanto se trata de un único delito que incluye desde la fabricación hasta el tráfico internacional, pasando por el porte (independientemente de si se trata de consumidores). 
costo para cada una de estas etapas. Para esto utilizándose utiliza el costo salarial por hora para los funcionarios que intervienen en el proceso: policías, fiscales, jueces y defensores públicos, así como los costos mensuales del sistema penitenciario y carcelario. Esta información se complementa con los datos correspondientes a la duración de cada etapa en audiencias, tiempo en detención preventiva, tiempo en establecimientos penitenciarios, entre otros. Los datos se obtuvieron a partir de una encuesta a 96 oficiales de la policía, entrevistas semiestructuradas con fiscales y la revisión de 20 expedientes relacionados con procesos por el delito de porte, fabricación y tráfico de estupefacientes que se llevaban en los juzgados de Bogotá.

Los datos anteriores permiten estimar que el costo esperado por una captura es cercano a los $\$ 11$ millones. Esto sugiere que entre 2001 y 2015 el gasto fiscal asociado a las capturas realizadas por la policía por el delito de porte, fabricación y tráfico de estupefacientes ascienden a $\$ 10,6$ billones en precios de 2016, mientras que el gasto promedio anual en los últimos cinco años fue de alrededor de $\$ 893.000$ millones. Para tener puntos de referencia en el análisis, se estimaron diversos costos asociados al consumo de drogas ilícitas, en particular, los relacionados con la atención en el sistema de salud, las pérdidas de productividad laboral y el crimen asociado al consumo. Para esto, se tuvo en cuenta un análisis realizado por el Departamento de Justicia de Estados Unidos (2011) para este país.

Se analizaron varias hipótesis que puedan llevar al gobierno a realizar este esfuerzo fiscal: la necesidad de combatir el tráfico internacional de drogas ilícitas (en particular de cocaína), el interés por evitar la violencia y el crimen asociados al consumo de drogas ilícitas o el deseo de disuadir a los consumidores mediante la persecución del delito de porte, fabricación y tráfico de estupefacientes. Se concluye que ninguna de estas situaciones justifica un esfuerzo fiscal tan elevado. Parte de la explicación a esto se encuentra en los incentivos definidos en la policía para motivar los resultados operativos en capturas e incautaciones de drogas ilícitas.

Este artículo es descriptivo y pretende contribuir a la discusión de política pública sobre el enfoque de la lucha contra las drogas. En general, muchas decisiones tomadas por gobiernos, tanto en Colombia como en otros países 
Gutiérrez y Tobón: El gasto fiscal de la guerra contra los portadores de drogas ilícitas:...

de la región (productores y consumidores), adolecen de herramientas de análisis e información imparcial que permita orientar mejor sus decisiones. Para darle estructura al análisis descriptivo, en este artículo se utilizan herramientas de literatura previa sobre la estimación de costos en el sistema de justicia criminal (Departamento de Justicia de Estados Unidos, 2011; Harwood, Napolitano, Kristiansen \& Collins, 1984; Harwood, Fountain \& Livermore, 1998, 1999; Harwood, Kallinis \& Liu, 2001; Office of National Drug Control Policy, 2001, 2004). Adicionalmente, este artículo contribuye a la literatura en economía y otras disciplinas sobre la legalización de las drogas, sus consecuencias y efectos. En este caso, sobre el costo de oportunidad asociado a dirigir esfuerzos del sistema de justicia criminal a la persecución al porte de drogas (véase, por ejemplo, Anderson, Hansen \& Rees 2013, 2015; Anderson \& Rees, 2014; Hall \& Lynskey, 2016; y MacCoun, Pacula, Chriqui, Harris \& Reuter, 2009).

Este artículo se compone de cinco secciones, incluida esta introducción. En la sección I se analiza el ciclo criminal del delito de porte, fabricación y tráfico de estupefacientes, y se describe la estimación realizada para los costos por etapa. En la sección II se construyen las probabilidades condicionales para que los procesos judiciales tomen las diversas rutas del ciclo; además, se estiman los costos esperados por captura y el costo total para el período 20012015. En la sección III se estiman otros costos sociales asociados al consumo de drogas ilícitas. Finalmente, se discuten las posibles hipótesis que motivan al gobierno colombiano a hacer estos los esfuerzos fiscales para la persecución del delito de porte, fabricación y tráfico de estupefacientes.

\section{El ciclo criminal}

El artículo 376 del Código Penal colombiano tipifica el delito de tráfico, fabricación o porte de estupefacientes. Este delito comprende sanciones tanto para los consumidores como para los traficantes internacionales de drogas ilícitas en grandes volúmenes. Aunque el porte ha sido castigado cuando excede las dosis mínimas establecidas, esta situación cambió con la decisión de la Corte Suprema de Justicia del 9 de marzo de 2016, cuando se señaló que el consumo no debe procesarse como un delito cuando quien porta las 
drogas ilícitas lo hace para consumirlo en razón de su enfermedad o adicción. En esta medida, el análisis que desarrollamos se enmarca en la jurisprudencia vigente hasta antes de la decisión de la Corte.

Antes de realizar una aproximación a los costos totales que ha implicado para el Estado la judicialización por el delito de tráfico, fabricación o porte de estupefacientes, en esta sección se describen las fases que componen el ciclo criminal de este delito, así como las agencias del Estado que intervienen en cada fase, y se discuten algunos de los costos generados. El ciclo criminal puede dividirse en cuatro fases que se presentan a continuación. Primero se presenta la fase de ocurrencia del delito; en segundo lugar, tiene lugar la fase de investigación criminal e imputación; luego empieza la fase procesal, que incluye la acusación y el juicio oral; finalmente, se presenta la fase de sentencia y ejecución de penas, con la que se cierra el ciclo criminal del delito de fabricación, porte y tráfico de estupefacientes.

\section{A. Fase de ocurrencia del delito y captura}

Con la identificación de un hecho delictivo cualquiera por parte de las autoridades, se da inicio a la intervención para recolectar las evidencias y el material probatorio destinado a la investigación de los responsables y su posterior judicialización, si procede. Esta fase se caracteriza por la intervención activa de la policía de vigilancia, quien, como responsable de mantener la seguridad y el orden, es usualmente la primera agencia del Estado que conoce de los hechos delictivos, activando el ciclo criminal.

La identificación de casos de ocurrencia del delito inicia por las denuncias que presentan los ciudadanos ante la policía de vigilancia o ante la Fiscalía. Estas pueden ser denuncias penales o solicitudes para que se retire a alguien del espacio público por estar consumiendo o vendiendo drogas ilícitas. Es posible también que la policía conozca de los hechos ilícitos como resultado de las actividades propias de vigilancia, ${ }^{5}$ casos en los que la captura se presenta en flagrancia. De acuerdo con los datos del Sistema de Información

5 La planeación del servicio de policía se realiza con la Tabla de Acciones Mínimas Requeridas. Esta planeación incluye también el establecimiento de metas y objetivos en función de los resultados operativos. En lo relacionado con el delito de fabricación, porte y tráfico de 
Gutiérrez y Tobón: El gasto fiscal de la guerra contra los portadores de drogas ilícitas:...

Estadística Delincuencial y Contravencional (SIEDCO), el 94\% de las capturas por el delito de tráfico, fabricación y porte de estupefacientes se dan de esta manera. En una encuesta que se realizó a 96 oficiales de la policía, se encontró que, generalmente (incluso con los cambios en el comportamiento policial que pudo traer la reciente decisión de la Corte sobre el tratamiento del consumo como un delito) cuando una patrulla de policía se encuentra a algún portador de una cantidad superior a las dosis mínimas establecidas, se procede con una captura.

El costo de una captura es, en la práctica, un costo de oportunidad; es decir, el costo de asignar funcionarios a este proceso y no a otro que podría generar un mayor bienestar social. En la encuesta realizada a los 96 oficiales, se indagó sobre la duración del tiempo promedio para trasladar un capturado a una estación de policía o a una fiscalía, y el tiempo promedio para realizar la judicialización de la captura. En promedio, los oficiales señalaron que el traslado toma 4 horas y la judicialización 5,5 horas. Esto implica que, en promedio, la realización de una captura le toma, a una patrulla de policía conformada por dos patrulleros 9,5 horas. Para 2016, el salario de un patrullero de la policía fue de $\$ 1.350 .270$, lo que deja el costo de oportunidad en personal de policía en aproximadamente $\$ 133.620$ por captura. ${ }^{6} \mathrm{El}$ proceso de judicialización de la captura implica la realización de una audiencia donde participan, además de los patrulleros, un fiscal, un defensor y un juez de control de garantías. Los costos adicionales asociados a la participación de estos actores se analizan en la fase de investigación e imputación.

\section{B. Fase de investigación e imputación}

La fase de investigación corresponde al período de recolección del material probatorio y las evidencias físicas que permitan inferir que la persona capturada es autora o partícipe de un delito. En este proceso participan los cuerpos de investigación, la defensa de la persona capturada y los jueces.

estupefacientes, se pretende maximizar el número de capturas y de incautaciones de drogas ilícitas.

6 La tabla de salarios de la Policía Nacional para 2016 se establece en el Decreto 214 de 2016. 
La policía judicial es el cuerpo de investigación encargado de desarrollar todas las actividades de campo para la recolección del material probatorio de un hecho. Esta cuenta con dos cuerpos: la Seccional de Investigación Criminal e Interpol (SIJIN) para los casos a nivel seccional y la Dirección de Investigación Criminal e Interpol (DIJIN) para casos a nivel nacional. Por su parte, la Fiscalía cuenta con su propio Cuerpo Técnico de Investigación (CTI). Cada fiscal cuenta con el apoyo de, por lo menos, un funcionario de policía judicial para el desarrollo de sus investigaciones. ${ }^{7}$

Cuando se le comunica a un capturado sobre los actos de investigación que se adelantan en su contra, se activa el derecho de defensa, lo que implica la aparición del defensor en el proceso como parte interviniente. La defensa está a cargo del abogado que designe libremente la persona o del defensor público que le sea asignado mediante el Sistema Nacional de Defensoría Pública. Cortés (2011) reporta que, en Colombia, alrededor del $74 \%$ de los capturados por cualquier delito son defendidos por defensores públicos.

Además, en la fase de investigación participan jueces con funciones de control de garantías, en particular en las denominadas audiencias preliminares. Entre estas audiencias se destaca la formulación de imputación, la definición de una medida de aseguramiento, la práctica de pruebas anticipadas y la definición de medidas de protección para una víctima o un testigo, entre otros. ${ }^{8}$

Sobre la base de la investigación, la Fiscalía decide si continúa con la imputación o aplica una forma de terminación anticipada del proceso a la persona capturada. Entre las formas de terminación anticipada se cuentan el archivo de la diligencia, la declaratoria de ilegalidad de la captura y el babeas

7 Sin embargo, en entrevistas de campo se encontró que el número de policías asignado no responde a la carga del fiscal, sino a la urgencia en las investigaciones. De esta manera, un fiscal de indagación que recibe en promedio 60 denuncias, sumado a un inventario de 800 procesos, solo puede solicitar, junto con sus compañeros, 20 órdenes para el desarrollo de sus investigaciones. Por su parte, un fiscal de una Unidad de Reacción Inmediata (URI) cuenta con el apoyo de tres miembros de policía judicial, de SIJIN y de DIJIN, para el desarrollo de casos urgentes.

8 El juez con funciones de control de garantías puede dictar y legalizar órdenes de captura adicionales que se deriven del proceso de investigación. 
Gutiérrez y Tobón: El gasto fiscal de la guerra contra los portadores de drogas ilícitas:...

corpus. El fiscal puede archivar la diligencia de manera anticipada porque determina que el hecho denunciado no existió o el bien jurídico tutelado no se ve afectado por la conducta. Además, puede ocurrir que una persona capturada en flagrancia no haya sido puesta a disposición de la Fiscalía de forma inmediata o a más tardar en el término de la distancia, o que esta misma entidad no haya puesto a la persona a disposición del juez de control de garantías dentro de las 36 horas siguientes para que se pronuncie sobre la legalidad de la aprehensión. ${ }^{9}$ En estos casos la persona es dejada en libertad, con la condición de que puede ser llamada en cualquier momento a indagatoria. Adicionalmente, si la persona permanece privada de la libertad ilegalmente por más de 36 horas sin ser puesta a disposición de la Fiscalía o la autoridad judicial competente, el capturado puede presentar el recurso de habeas corpus, por medio del cual, si se resuelve a su favor, puede ser dejado en libertad. ${ }^{10}$

De acuerdo con información que la Fiscalía suministró para el desarrollo de este trabajo, de todos los capturados puestos a disposición de esta entidad entre 2008 y 2015, en el $69 \%$ de los casos no se dio la imputación y, por el contrario, se dio por terminado el proceso de manera anticipada. En el restante 31 \% se llegó a la audiencia de formulación de imputación.

Adicionalmente, de acuerdo con información de la Fiscalía reportada por el Ministerio de Justicia y del Derecho (2013), entre los imputados por el delito de tráfico, fabricación y porte de estupefacientes en el período 2008 2012, para el $25 \%$ se determinó proceder con una medida de aseguramiento. Entre ellos, el $70 \%$ de los capturados tuvieron detención preventiva en establecimiento carcelario, el 22\% detención domiciliaria y el $8 \%$ otras medidas no privativas de la libertad, como los mecanismos de vigilancia electrónica o la prohibición de salir del país o la región donde reside. Es decir, entre los imputados, alrededor del $18 \%$ fueron asignados a medidas de detención preventiva en establecimientos carcelarios.

Los costos de la fase investigativa revisten mayor complejidad en el análisis que los correspondientes a la fase de ocurrencia del delito y captura.

$9 \quad$ Así lo señala el artículo 302 del Código de Procedimiento Penal colombiano.

10 Así lo determina el artículo 30 de la Constitución Política colombiana. 
No obstante, puede simplificarse en razón a las circunstancias en que se dan las capturas. De acuerdo con la información suministrada por los fiscales entrevistados, usualmente, cuando las capturas se dan en flagrancia y no por orden judicial, se realizan de manera simultánea las audiencias de legalización de captura, legalización de incautación si esta procede, formulación de imputación y solicitud de medida de aseguramiento. Esto implica que los costos del despliegue de los equipos de investigación judicial son mínimos (o nulos) en tanto el material probatorio se recolecta al momento de la captura. Como la información de SIEDCO indica que el $94 \%$ de las capturas por el delito de tráfico, fabricación y porte de estupefacientes se dan por flagrancia, para el análisis que presentamos a continuación asumimos que siempre se presenta así.

A partir de las entrevistas desarrolladas con fiscales en la ciudad de Bogotá, se estimó que la realización de las audiencias de manera simultánea tiene una duración promedio de dos horas. Para 2016, el salario de fiscales delegados ante jueces de circuito fue de $\$ 6.873 .379$, el de un juez de circuito es de $\$ 5.516 .606$ y los honorarios de un defensor público son de alrededor de $\$ 4.300 .000 .{ }^{11}$ Así, el costo de oportunidad de la fase investigativa y de imputación es de $\$ 162.208 .{ }^{12}$ Este costo se genera para el $31 \%$ de las capturas, donde se procede a esta etapa. Los costos atribuibles a la imposición de medidas de aseguramiento en centro carcelario se analizan en la fase de ejecución de penas.

\section{Fase procesal}

Superada la etapa de imputación e investigación, el fiscal puede realizar la solicitud de terminación anticipada del proceso, si concluye que las circunstancias ameritan la preclusión, el juez de conocimiento la resuelve. Esto ocurre si, por ejemplo, el fiscal encuentra que hay una causal excluyente

\footnotetext{
11 Los salarios de fiscales se establecen en el Decreto 219 de 2016 y los salarios de la Rama Judicial se establecen en los decretos 234 y 246 de 2016. La información de honorarios de los defensores públicos se aproximó teniendo en cuenta la resolución 117 de 2008.

12 Utilizamos el $74 \%$ del costo por hora para el caso de los defensores, ya que, aproximadamente, este es el número de casos donde participan defensores públicos.
} 
Gutiérrez y Tobón: El gasto fiscal de la guerra contra los portadores de drogas ilícitas:...

de responsabilidad. En la información entregada por la Fiscalía, se encontró que de todos los procesos que ingresaron por el delito de porte, fabricación y tráfico de estupefacientes, entre 2008 y 2015, alrededor del 15\% de las veces se dio terminación anticipada del proceso por preclusión.

Alternativamente, el fiscal puede presentar ante el juez de conocimiento todos los elementos materiales probatorios y evidencias físicas a través de los cuales se pueda afirmar que la conducta delictiva existió y que el imputado es autor o partícipe del delito, lo cual corresponde al $85 \%$ de los casos que no precluyen. Esta etapa inicia con la presentación que el fiscal hace del escrito de acusación, mediante el cual el juez convoca a la respectiva audiencia. El juez de conocimiento es entonces quien tiene a su cargo la responsabilidad de absolver o condenar a quien se le demuestre la comisión del delito.

Durante la acusación, el fiscal presenta a la defensa todas las evidencias físicas y el material probatorio recolectado que sustentan la comisión del delito, a partir de lo cual se podrán celebrar preacuerdos y negociaciones entre la Fiscalía y el acusado, de manera que se adopte una decisión anticipada sin necesidad de llevar el proceso hasta el juicio oral. Finalizada la audiencia de acusación, se cita a la audiencia preparatoria donde además de la confirmación de hechos por las partes, el acusado tiene la oportunidad de aceptar la comisión del delito; en este caso también se puede dar por terminado de forma anticipada el proceso. De acuerdo con la información de actuaciones suministrada por la Fiscalía, para los casos que ingresaron entre 2008 y 2015, alrededor del $67 \%$ fueron terminados por aceptación de cargos o celebración de preacuerdos. Lo anterior se explica porque, como señalamos antes, gran parte de las capturas por estupefacientes se dan en flagrancia (94\%), lo que incrementa la probabilidad de una sentencia condenatoria e incentiva a aceptar los cargos.

El restante $33 \%$ de los casos, continúan hacia la realización de la audiencia de juicio ante el juez de conocimiento, donde el fiscal y el defensor deben exponer sus teorías del caso y las pruebas que lo sustentan. Con base en estas teorías, el juez valora si existe un convencimiento más allá de toda duda razonable que permita constatar la ocurrencia del hecho. 
Para la estimación de los costos de la fase procesal, se tuvo en cuenta la información suministrada por 96 oficiales de policía encuestados. De acuerdo con esta información, en promedio, los patrulleros deben atender 11 horas de audiencias relacionadas con los procesos por porte, fabricación y tráfico de estupefacientes, que toman desde unas pocas semanas hasta uno o dos años, dependiendo del caso. Adicionalmente, se revisaron 20 expedientes de los juzgados en Bogotá relativos a casos por este delito, y se corroboró que, además de los patrulleros, también es usual la presencia del fiscal, el juez y el defensor. En estos expedientes también se verificó la duración aproximada de las audiencias y se confirmó el estimado que aquí se usa a partir de lo reportado por los oficiales. Con estos supuestos, el costo de la fase procesal y de acusación es de $\$ 1.046 .863 .{ }^{13}$

Adicionalmente, asumimos que este sería el costo de una fase procesal que no se interrumpe por la aceptación de cargos o la celebración de preacuerdos. En este último caso el costo sería presumiblemente menor, ya que no es necesario prolongar el proceso e incrementar el número de audiencias. De acuerdo con la información de fechas para cada una de las actuaciones en casos por porte, fabricación y tráfico de estupefacientes suministrada por la Fiscalía, se estima que los procesos que terminan con la aceptación de cargos o la celebración de acuerdo duran, en promedio, el $55 \%$ del tiempo que dura un proceso en donde no se presenta la interrupción. En esta medida, se estima que el costo de los procesos donde se da la aceptación de cargos o celebración de preacuerdos tienen un costo de $\$ 574.125$.

\section{Fase de sentencia y ejecución de penas}

Como mencionamos antes, es el juez de conocimiento quien decide sobre la culpabilidad o no de la persona sindicada. De acuerdo con la información suministrada por la Fiscalía, entre todos los casos que ingresaron entre 2008 y 2015 por porte, fabricación y tráfico de estupefacientes que llegaron hasta la audiencia de acusación y en los que no hubo aceptación

13 Como se hizo para la fase de investigación e imputación, aquí se asume el $74 \%$ del costo por hora para el caso de los defensores públicos, pues estos son los casos en que la defensa la asume un defensor público. 
Gutiérrez y Tobón: El gasto fiscal de la guerra contra los portadores de drogas ilícitas:...

de cargos o celebración de acuerdos, alrededor del $73 \%$ terminaron con una sentencia condenatoria y el restante $27 \%$ con una sentencia absolutoria. En cualquiera de estos casos se generan los costos asociados a la celebración de las audiencias, del juicio oral y de la lectura de sentencia, que, de acuerdo con la información suministrada por fiscales en las entrevistas celebradas en Bogotá, tienen una duración promedio de 4 horas para el juicio oral y 1 hora para la lectura de sentencia. Estas audiencias se celebran con la presencia del fiscal, el juez de ejecución de penas y el defensor, por lo que su costo se estima en $\$ 405.520 .{ }^{14}$

A su vez, de acuerdo con la información de la Sistematización Integral del Sistema Penitenciario y Carcelario (SISIPEC) del INPEC, entre las personas que han pasado por el sistema entre 2009 y 2016 y que han recibido una sentencia condenatoria por el delito de porte, fabricación y tráfico de estupefacientes y han cumplido su condena, el $73 \%$ estuvo recluido en un establecimiento penitenciario. ${ }^{15}$ En el $27 \%$ restante de los casos, la condena implicó medidas alternativas, como el monitoreo electrónico o la detención domiciliaria. ${ }^{16}$ El tiempo promedio efectivo de reclusión de la población condenada es de 82 meses. Este tiempo incluye el período de detención preventiva cuando la hubiere.

Para el $27 \%$ de la población que recibe sentencia absolutoria, se procede a otorgar su libertad. El tiempo efectivo promedio de reclusión de la población que no fue condenada, pero tenía medida de aseguramiento en establecimiento carcelario, es 18 meses, de acuerdo con la información del SISIPEC. El costo de la reclusión en establecimientos penitenciarios y carcelarios tiene diversos componentes. Los internos, tanto sindicados como condenados, requieren la provisión de seguridad, servicios de saneamiento

14 Como en casos anteriores, se toma el $74 \%$ del costo por hora de los defensores, ya que es en estos casos en los que se dispone de defensores públicos.

15 Para este análisis y todo lo relacionado con la información del SISIPEC, se incluyeron internos condenados o sindicados únicamente por el delito de porte, fabricación y tráfico de estupefacientes, y no por otros delitos.

16 Las personas con medidas alternativas como el monitoreo electrónico son, en cualquier caso, asignadas a algún establecimiento carcelario y penitenciario. Por esta razón, el SISIPEC contiene información tanto de quienes tienen medidas de reclusión como quienes no la tienen. 
y alcantarillado, y alimentación. Además, es preciso administrar programas de resocialización al interior de los establecimientos, y disponer de espacios para el deporte y otras actividades. Estos costos se estimaron a partir del presupuesto anual del INPEC y el número de internos, de forma que se consideran incluso los costos de administración del sistema. En particular, se toma el presupuesto promedio del INPEC entre los años 2010 y 2015, equivalente a $\$ 1.067$ billones en precios de 2016 , y la población promedio para el mismo período, que fue alrededor de 109 mil internos. Con base en este análisis se estimó que el costo mensual por interno es de $\$ 851.163$.

\section{Los costos sociales de la persecución al delito de porte, fabricación y tráfico de estupefacientes}

La motivación principal de este trabajo es hacer una aproximación del costo social derivado de la persecución al delito de porte, fabricación y tráfico de estupefacientes. Este costo social se estima a partir del gasto público asociado a las acciones de persecución del delito. Para realizar esta estimación, el análisis puede tomar dos perspectivas: el método basado en la prevalencia o el método basado en la incidencia. ${ }^{17} \mathrm{El}$ análisis basado en prevalencia consiste en cuantificar los costos que se observan en una ventana de tiempo presente, producto de todas las situaciones presentes y pasadas asociadas a la persecución del delito. Por otra parte, el método basado en la incidencia hace referencia a los costos presentes y futuros causados por las situaciones o los hechos actuales. Es necesario utilizar alguno de estos enfoques, pues no todos los costos se realizan en un mismo período de tiempo. Por ejemplo, si se hace efectiva una captura en un momento específico y la captura lleva a una condena en prisión, los costos asociados a esa captura pueden realizarse hasta 5 o más años después. Este enfoque consiste en estimar los costos de la persecución al delito de porte, fabricación y tráfico de estupefacientes utilizando el costo esperado por captura; en esta medida, se utiliza el método basado en la incidencia y se estiman los costos presentes y futuros a partir de los hechos que se presentan en una ventana de tiempo dada.

17 Para ampliar la discusión sobre estos enfoques, véase Departamento de Justicia de Estados Unidos (2011). 
Gutiérrez y Tobón: El gasto fiscal de la guerra contra los portadores de drogas ilícitas:...

Para realizar la estimación se calcula inicialmente el costo esperado de una captura. Para ello, en primera instancia, se construye la Figura 1, a partir de la información presentada en la sección II. Es decir, se muestran las probabilidades condicionales de seguir los diferentes caminos del ciclo criminal una vez se presenta una captura por el delito en cuestión. Como se observa en la figura, una vez se presenta una captura, la probabilidad de que se presente una imputación y continúe el proceso es del $31 \%$. Condicional en la imputación, la probabilidad de preclusión del proceso en la fase procesal es del $15 \%$, y la probabilidad de que el proceso continúe es del $85 \%$. Si el proceso no precluye, la probabilidad de aceptación de cargos y celebración de acuerdos entre el acusado y la Fiscalía es del $67 \%$, y la probabilidad de no aceptación de cargos y continuación del juicio es del $33 \%$. Cuando se aceptan los cargos, asumimos una sentencia condenatoria con una probabilidad del $100 \%$. Condicional en la continuación del juicio, la probabilidad de una sentencia absolutoria es del $27 \%$, y la de una condenatoria del $73 \%$. Finalmente, condicional en una sentencia condenatoria, la probabilidad del otorgamiento de medidas alternativas, como el monitoreo electrónico o la prisión domiciliaria, es del $27 \%$, y la probabilidad de una medida intramural en establecimiento penitenciario es del $73 \% .{ }^{18}$ Adicionalmente, como anotamos en la figura, si se presenta la imputación, existe una probabilidad del $74 \%$ de la asignación de un defensor público al caso y una probabilidad del $18 \%$ de que el juez apruebe una medida de aseguramiento en establecimiento carcelario durante el proceso. La información para estos porcentajes se estimaron a partir de las actuaciones registradas en el sistema de información de la Fiscalía General de la Nación entre 2008 y 2015, el INPEC y el Ministerio de Justicia y del Derecho (2013). ${ }^{19}$

Por otra parte, se utilizaron los costos estimados para cada una de las etapas que registradas en la sección II. Esta estimación se hizo a partir de los salarios de personal de policía, fiscalía, juzgados y defensoría pública, así como

18 Se asume que esta distribución es la misma para quienes aceptan cargos y para quienes, sin aceptarlos, son condenados en el juicio, pues la información del INPEC con la que se estima esta distribución no discrimina entre ambos casos.

19 Dado que no se tiene conocimiento de fuentes alternativas de información, no oficiales, que hagan estimaciones similares con un tama no de muestra suficientemente grande, se consideran únicamente fuentes oficiales para Colombia. 
el gasto fiscal y la población del sistema penitenciario y carcelario colombiano. En particular, se estimó que, por evento, los costos de la fase de ocurrencia del delito y captura son de $\$ 133.620$; los de la fase de investigación e imputación son de $\$ 162.208$, si se presenta la imputación; y los de la fase procesal son de $\$ 574.125$ si la persona acepta los cargos y celebra un preacuerdo, pero se elevan a $\$ 1.046 .863$, si se continúa con el juicio oral. A su vez, los costos asociados al sistema penitenciario y carcelario son de $\$ 851.163$ mensuales. Estos costos aplican por 18 meses para el 18\% de los imputados que tienen medida de aseguramiento en establecimiento carcelario, y se extienden hasta 82 meses para quienes reciben una sentencia condenatoria con una medida intramural en establecimiento penitenciario.

Figura 1. Probabilidades condicionales en el ciclo criminal por porte, fabricación y tráfico de estupefacientes

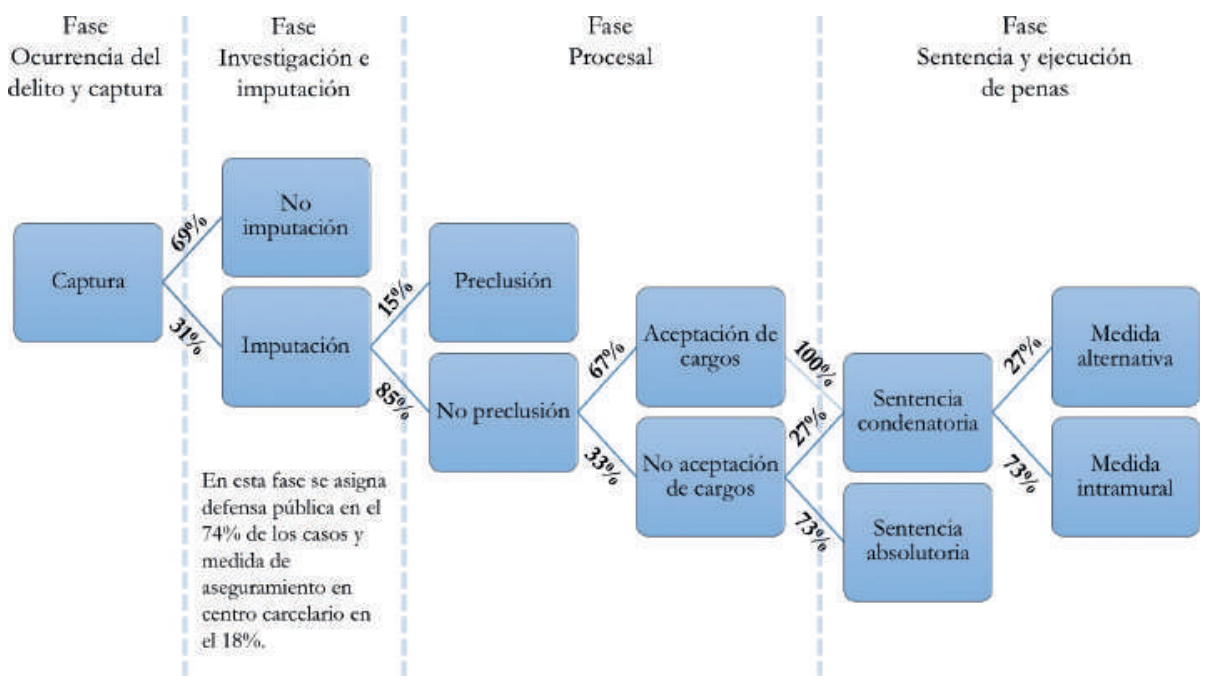

Fuente: cálculos propios a partir de la información de la Fiscalía General de la Nación entre 2008 y 2015, el INPEC y el Ministerio de Justicia y del Derecho (2013).

A partir de la información de probabilidades condicionales y costos por etapa, es posible estimar el costo esperado de una captura. Es importante precisar que este costo se entiende como una subestimación del costo real, ya que únicamente se considera el involucramiento de los actores principales 
Gutiérrez y Tobón: El gasto fiscal de la guerra contra los portadores de drogas ilícitas:...

por parte de agencias del Estado, es decir: policías, fiscales, jueces, defensores públicos y todo lo asociado al sistema penitenciario y carcelario. Esto deja por fuera la participación de personal asistencial o superior que debe involucrarse regularmente. Adicionalmente, no se consideran los esfuerzos de persecución del delito. En la encuesta realizada a 96 oficiales de la policía, el $60 \%$ indicó que cada cuadrante dedica más de 10 horas semanales a las actividades de persecución del consumo en respuesta a llamadas ciudadanas y a requisa en búsqueda de estupefacientes, entre otras relacionadas. También es importante señalar que estos costos pueden variar de un año a otro, según cambie el enfoque de la política criminal, que puede volverse más o menos punitivo en alguna de las etapas. No obstante, como se utilizó información tanto de la Fiscalía como del INPEC que cubría un espacio amplio de tiempo en la última década, se consideró que este costo puede extenderse a las capturas realizadas en diferentes años, con menor precisión para los años anteriores a la disponibilidad de los datos. De acuerdo con la información recolectada, el costo estimado por la realización de una captura es de $\$ 10.776 .002$; este costo se encuentra en precios reales de 2016, pues todas las fuentes de información en precios se ajustaron a este año.

Entre 2001 y 2015, en Colombia se realizaron 984.106 capturas por el delito de porte fabricación y tráfico de estupefacientes, (aunque estas cifras no discriminan la motivación específica (por ejemplo, tráfico o fabricación). La Figura 2 presenta las cifras anuales de capturas por este delito, de acuerdo con varios informes publicados la Revista Criminalidad (Aparicio, 2009; BarcoPérez \& Arana-Cosme, 2014; Buitrago, Bernal \& Rodríguez, 2015; Buitrago \& Norza-Céspedes, 2016; Duarte-Velásquez, 2013; Espino-Duque, 2010; Norza-Céspedes \& Espino-Duque, 2011; Norza-Céspedes \& López-Guaje, 2012; Rodríguez, 2008). El año con más capturas por este delito fue 2013, cuando se presentaron 91.148. A su vez, el año con menos capturas fue 2001, con 28.956 . 
Figura 2. Capturas por el delito de porte, fabricación y tráfico de estupefacientes en

\section{Colombia}

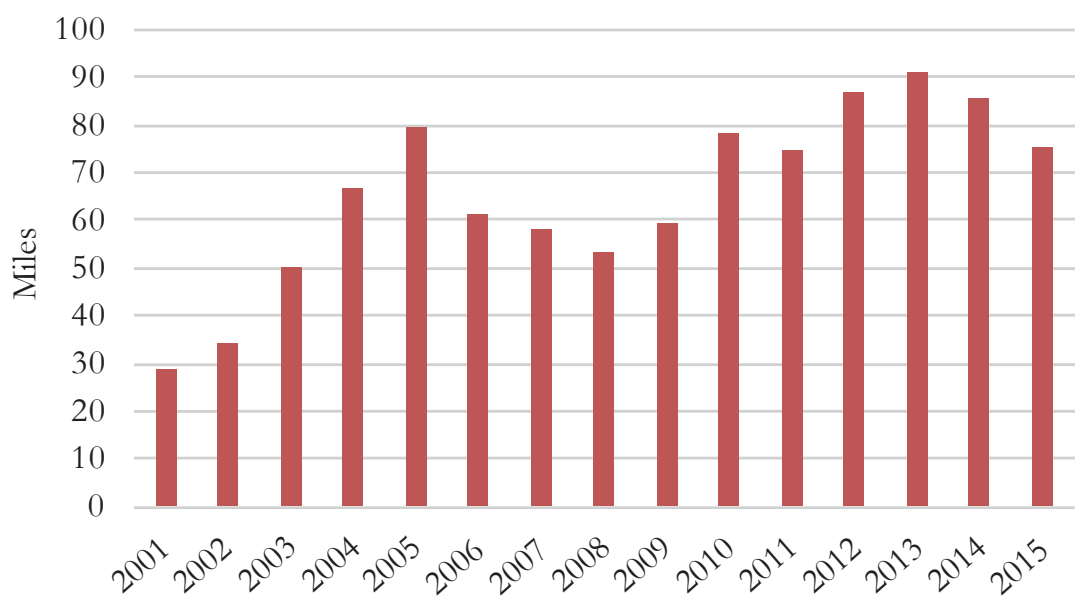

Fuente: Construcción propia con base en los informes publicados en la Revista Criminalidad.

Así, de acuerdo con las estimaciones que aquí se presentan, entre 2001 y 2015 el gasto fiscal asociado a las capturas por el delito de porte, fabricación y tráfico de estupefacientes ascienden a $\$ 10,6$ billones. ${ }^{20}$ Así, En los últimos cinco años, el gasto promedio fue de alrededor de $\$ 893.000$ millones. La Figura 3 presenta el costo anual, resultado de multiplicar el costo por captura por el número de capturas anuales.

Estos gastos no discriminan lo correspondiente a fabricación, porte o tráfico de drogas. Presumimos, como se discute en la sección IV, que se trata, en su mayoría, de casos de porte o microtráfico, pues usualmente las dosis incautadas a los capturados están alrededor del umbral de la dosis mínima. Además, menos del 10\% de los 96 oficiales de la policía encuestados (que habían desempeñado roles comandando CAI o estaciones) no conocían las cantidades mínimas para al menos tres tipos de droga diferentes. Esto lleva, inherentemente, a la imposibilidad de discriminar con base en cantidades u otra variable objetiva. El costo esperado de estas capturas es relativamente

$\overline{20}$ No todos los costos se han realizado, pues no todos los procesos judiciales han terminado 
Gutiérrez y Tobón: El gasto fiscal de la guerra contra los portadores de drogas ilícitas:...

grande; por ejemplo, el presupuesto anual de la Policía Nacional para 2016 fue alrededor de $\$ 16$ billones.

Figura 3. Costo derivado de las capturas anuales por el delito de porte, fabricación y tráfico de estupefacientes

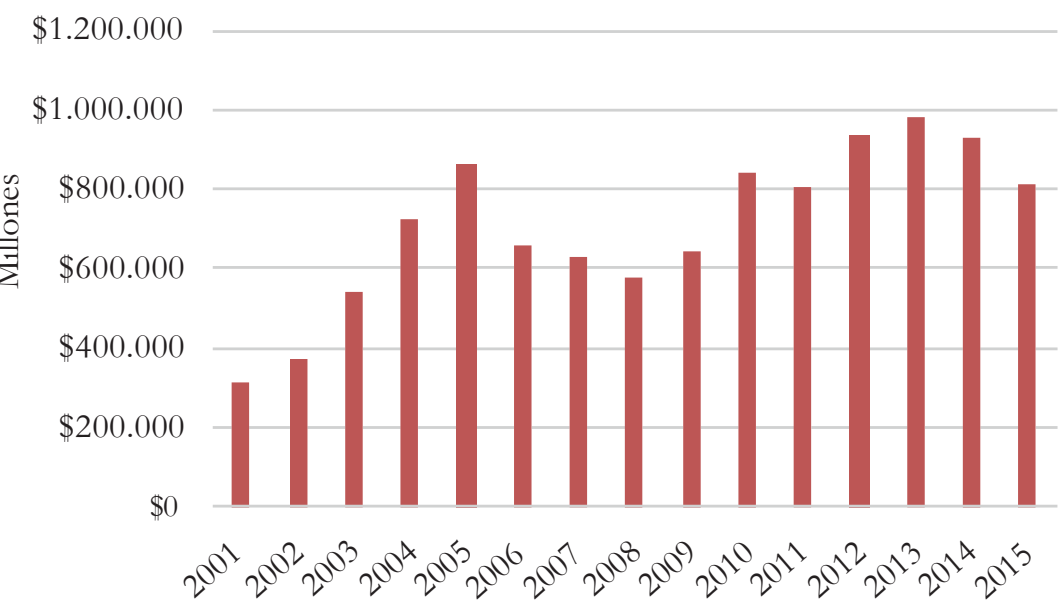

Fuente: construcción propia a partir de los informes publicados en la Revista Criminalidad, datos de la Fiscalía General de la Nación entre 2008 y 2015, el INPEC y de Ministerio de Justicia y del Derecho (2013).

\section{Otros costos sociales asociados al consumo de drogas ilícitas}

Para complementar el análisis sobre los costos asociados al sistema de justicia criminal relacionados con la persecución al delito de porte, fabricación y tráfico de estupefacientes, en esta sección se presenta una estimación de otros costos sociales asociados al consumo de drogas ilícitas; la aproximación consiste en la cuantificación de los recursos económicos utilizados o perdidos como resultado de dicho consumo. Este ejercicio es complementario al anterior, relacionado con el sistema de justicia criminal, y pretende ofrecer puntos de referencia sobre algunas de las cifras presentadas en la sección II.

Los costos analizados comprenden varios elementos: primero, los costos directos que incluyen la atención en salud, la destrucción del capital relacionado con el crimen, la investigación y las políticas de prevención, 
entre otros y, segundo, los costos indirectos relacionados con las pérdidas de productividad, con la muerte prematura y las enfermedades conexas al consumo de drogas ilícitas. Estas últimas pueden estar influenciadas también por otros factores, por lo que se atribuye un factor de causalidad por consumo de drogas ilícitas para aislar su efecto. El marco de referencia para este trabajo es el propuesto por el Departamento de Justicia de Estados (2011), en un ejercicio similar realizado para este país. Adicional a lo anterior, al consumo de drogas ilícitas se asocian costos intangibles como, por ejemplo, los costos por el dolor, la pena o las pérdidas de calidad de vida. Sin embargo, en este trabajo no se tienen en cuenta por la complejidad de su estimación y porque rara vez se incluyen en este análisis. Por la disponibilidad de los datos, en este caso, la estimación se realiza con base en los eventos que se presentaron en el año 2010.

La desagregación de los costos se realiza en tres componentes: primero, estimamos los costos sociales asociados a la salud, que incluyen los costos por tratamiento especializado para el consumo de drogas ilícitas y el tratamiento para enfermedades que dicho consumo induce; segundo, estimamos los costos asociados a las pérdidas de productividad que el consumo de drogas ilícitas genera; tercero, estimamos los costos sociales asociados a crímenes cometidos en función de este consumo ilícito. Para los tres componentes nos basamos en la estimación del Departamento de Justicia de Estados Unidos (2011). Estos costos, cabe aclarar, no corresponden a un ejercicio exhaustivo, por lo que se dejan por fuera otros costos sociales asociados al consumo.

\section{A. Costos sociales en salud}

Estos costos corresponden a los recursos que se habrían podido destinar a otras actividades distintas a la atención médica por el consumo de drogas; es decir, como en el caso de los costos asociados al sistema de justicia criminal, se trata de un costo de oportunidad. En este trabajo se construye el costo de oportunidad a partir de la metodología utilizada por el Departamento de Justicia de Estados Unidos (2011), y se utilizan como insumos los gastos en asistencia médica del Sistema General de Seguridad Social en Salud (SGSS) de Colombia, pues son recursos que habrían podido destinarse a otros fines. 
Gutiérrez y Tobón: El gasto fiscal de la guerra contra los portadores de drogas ilícitas:...

El costo de oportunidad atribuible a la asistencia médica por consumo de drogas ilícitas se divide en los siguientes elementos: gastos relacionados con tratamiento especializado del consumo de drogas ilícitas, gastos relacionados con el tratamiento de enfermedades que este consumo induce, y otros gastos relacionados con la atención, en los niveles nacional, departamental y municipal.

La fuente principal de información que utilizamos para esta estimación corresponde a los Registros Individuales de Prestación de Servicios de Salud (RIPS) del año 2010, los cuales reportan las atenciones realizadas por el SGSS. Estos datos incluyen la información del servicio utilizado (hospitalizaciones, urgencias o procedimientos), del motivo de la atención (el diagnóstico asociado al evento) y el valor del servicio. Los diagnósticos de las patologías son codificados a partir de la Clasificación Internacional de Enfermedades en su décima versión (CIE-10), a partir de la cual se identificaron los diagnósticos que indican asociación con el consumo de drogas ilícitas. Entre las enfermedades identificadas se encuentran los desórdenes mentales, el envenenamiento autoinfligido, el envenenamiento accidental o el envenenamiento indeterminado inducidos por el uso de drogas ilícitas. También se identificaron los diagnósticos de enfermedades relacionadas, como la hepatitis $\mathrm{B}$, la hepatitis $\mathrm{C}$, el VIH y la tuberculosis. Además de los RIPS, se utilizó la información de procedimientos, cifrada con la Codificación Única de Procedimientos (CUPS). De esta información se identificaron los procedimientos relacionados con consumo de drogas o algún desorden mental, como, por ejemplo, las pruebas de inteligencia y de personalidad.

A partir de la información de los diagnósticos, se construyeron tres niveles de atribución de causalidad al consumo de drogas ilícitas, denominadas atribución $\mathrm{A}$, atribución $\mathrm{B}$ y atribución $\mathrm{C}$, como lo hace el Departamento de Justicia de Estados Unidos (2011). La atribución A corresponde a la proporción del total de casos que tiene como diagnóstico principal el abuso de drogas ilícitas a partir de los registros RIPS o CUPS. Por ejemplo, de acuerdo con la información de los registros CUPS, 8 de cada 1.000 procedimientos asociados a casos de salud mental tienen una relación directa con el consumo de drogas ilícitas; en este caso, la atribución A de los casos de salud mental 
es 0,008. La atribución B corresponde a la proporción del diagnóstico efectivamente causado por el consumo de drogas ilícitas. Si en el diagnóstico principal se encuentra una asociación directa al consumo de drogas ilícitas, como en el ejemplo de la salud mental, la atribución B es por definición 1; en ese caso, la atribución de causalidad se encuentra determinada completamente por la atribución A. Sin embargo, cuando el diagnóstico es diferente, la atribución $\mathrm{B}$ es menor que 1; esta situación se presenta para los casos en donde no se trata de diagnósticos que permitan una asociación directa al consumo de drogas ilícitas. La atribución $\mathrm{C}$ es el producto de la atribución A por la atribución B. Es decir, la atribución $C$ corresponde al factor final de atribución al consumo de drogas ilícitas. Teniendo en cuenta las fuentes de información y los parámetros que se construyeron para analizar los costos de la asistencia médica para consumidores de drogas ilícitas, a continuación se presenta cada uno de los costos.

\section{Tratamiento especializado}

Los costos directos relacionados con el tratamiento médico especializado por el abuso de drogas ilícitas hacen referencia a los costos de prestación del servicio en que incurre el SGSS, los cuales se dividen entre los costos de procedimientos para detectar el consumo de sustancias psicoactivas y los costos de atención en salud mental a pacientes ya diagnosticados.

La primera columna de la Tabla 1 expone el total de eventos de tratamiento especializado por tomas de muestras y casos de salud mental en el año 2010 y que, de acuerdo con la información de los RIPS y CUPS, se encuentran asociados con el consumo de drogas ilícitas. El elemento de toma de muestras corresponde, en general, a toma de muestras de sangre para detectar la presencia de algún estupefaciente, mientras que el elemento de salud mental corresponde a pruebas de inteligencia y de personalidad. La atribución A de toma de muestras toma el valor de 1 porque este procedimiento se hace bajo la sospecha de que ha habido un consumo previo de drogas ilícitas; esta atribución en salud mental es de 0,008 , y se construyó a partir de la proporción de eventos a los que se encuentra asociado el consumo de drogas ilícitas, de acuerdo con la información de los RIPS y CUPS. Los costos por evento en que incurren los centros de salud que prestan cada servicio se aproximaron 
Gutiérrez y Tobón: El gasto fiscal de la guerra contra los portadores de drogas ilícitas:...

a partir del promedio de precios de un examen de toxicología en distintos laboratorios clínicos y entidades prestadoras de salud. ${ }^{21}$ Por su parte, el costo de los procedimientos en salud mental se estima como el precio promedio de una sesión de una hora de atención psiquiátrica. ${ }^{22}$ Es preciso señalar que estos valores corresponden a aproximaciones que sobreestiman el costo efectivo promedio, información de la que no se dispone. El costo atribuible al tratamiento especializado por consumo de drogas ilícitas en 2010 fue de cerca de $\$ 1.800$ millones, de acuerdo con la metodología definida para la estimación.

Tabla 1. Costos atribuibles al consumo de drogas ilícitas por tratamiento especializado

\begin{tabular}{lcccccc}
\hline & $\begin{array}{c}\text { Número de } \\
\text { eventos }\end{array}$ & $\begin{array}{c}\text { Atribución } \\
\text { A }\end{array}$ & $\begin{array}{c}\text { Atribución } \\
\text { B }\end{array}$ & $\begin{array}{c}\text { Atribución } \\
\text { B }\end{array}$ & $\begin{array}{c}\text { Costo por } \\
\text { evento }\end{array}$ & Total \\
\hline $\begin{array}{l}\text { Toma de } \\
\text { muestras }\end{array}$ & 9.162 & 1,000 & 1,000 & 1,000 & $\$ 180.000$ & $\$ 1.649 .160 .000$ \\
Salud mental & 127.448 & 0,008 & 1,000 & 0,008 & $\$ 130.000$ & $\$ 132.545 .920$ \\
Total & 136.610 & - & - & - & - & $\$ 1.781 .705 .920$ \\
\hline
\end{tabular}

Fuente: construcción propia con base en la información de los RIPS y CUPS. Precios de 2010.

\section{Hospitalizaciones y sala de emergencia}

Se estimaron los costos relacionados con la asistencia médica a pacientes que sufrieron de abuso de drogas o de alguna enfermedad relacionada, y que ingresaron al sistema de salud por hospitalizaciones o por sala de emergencias. Para este análisis se tuvieron en cuenta los pacientes de los registros RIPS que ingresaron por consumo problemático de drogas o por alguna enfermedad relacionada como hepatitis $\mathrm{B}$, hepatitis $\mathrm{C}$, VIH o tuberculosis, como se aprecia en el en el panel A de la Tabla 2, correspondiente a hospitalizaciones. La columna de número de eventos hace referencia al número de días que estuvieron internados los pacientes. Cuando algún usuario entró y salió el mismo día del hospital, contamos el día completo. Así mismo, se tiene en cuenta el día de entrada y de salida.

21 Un examen de toxicología es una prueba que se hace para detectar la presencia de distintas drogas ilícitas.

22 Ambos valores fueron estimados con base en una muestra no representativa de llamadas a diversos centros de atención en salud. Se encuentran en valores reales de 2010. 
Tabla 2. Costos atribuibles al consumo de drogas ilícitas por hospitalizaciones y atención en sala de emergencias

\begin{tabular}{lcccccc}
\hline & $\begin{array}{c}\text { Número de } \\
\text { eventos }\end{array}$ & Atribución & Atribución & Atribución Costo por & \multirow{2}{*}{ Total } \\
\hline A. Hospitalizaciones & & B & C & evento & \\
\hline Uso de drogas & 2.564 & 1,000 & 1,000 & 1,000 & $\$ 31.495 .304$ & $\$ 80.738 .211 .394$ \\
Hepatitis & 455 & 0,181 & 1,000 & 0,181 & $\$ 72.398 .567$ & $\$ 5.962 .383 .992$ \\
VIH & 5.397 & 0,213 & 1,000 & 0,213 & $\$ 99.576 .273$ & $\$ 114.458 .394 .633$ \\
Tuberculosis & 663 & 0,048 & 1,000 & 0,048 & $\$ 153.941 .177$ & $\$ 4.895 .329 .430$ \\
Otros & 822.075 & 0,029 & 0,100 & 0,003 & $\$ 53.404 .172$ & $\$ 127.316 .404 .043$ \\
Sub-total & 831.152 & - & - & - & - & $\$ 333.370 .723 .492$ \\
\hline B. Sala de emergencia & & & & & \\
\hline Uso de drogas & 3.414 & 1,000 & 1,000 & 1,000 & $\$ 3.918 .876$ & $\$ 13.379 .041 .025$ \\
VIH & 1.470 & 0,002 & 1,000 & 0,002 & $\$ 4.296 .713$ & $\$ 12.632 .336$ \\
Otros & 2.677 .975 & 0,001 & 0,100 & 0,000 & $\$ 2.792 .958$ & $\$ 747.947 .245$ \\
Sub-total & 2.682 .859 & - & - & - & - & $\$ 14.139 .620 .606$ \\
Total & 3.514 .011 & - & - & - & - & $\$ 347.510 .344 .098$ \\
\hline
\end{tabular}

Fuente: construcción propia con base en la información de los RIPS y CUPS, así como en el Departamento de Justicia de Estados Unidos (2011). Precios de 2010.

En este caso, para las atribuciones A y B se tomaron los parámetros del Departamento de Justicia de Estados Unidos (2011), construidos a partir del porcentaje de usuarios que recibieron atención de la enfermedad y que tuvieron como diagnóstico principal consumo de drogas ilícitas. Esta información no puede ser estimada para Colombia porque la información de diagnósticos secundarios no se encuentra completa en los RIPS a los que se accedieron en el desarrollo de este trabajo. En esta medida, se supone que las atribuciones son las mismas para Colombia que para Estados Unidos. ${ }^{23}$ Para los pacientes que entraron por uso de drogas esta es 1 por definición. También se tomó el costo por evento del Departamento de Justicia de Estados Unidos

23 Los valores del reporte del Departamento de Justicia de Estados Unidos (2011) se ajustan por la inflación para este país y luego se ajustan por la tasa de cambio promedio para 2010. 
Gutiérrez y Tobón: El gasto fiscal de la guerra contra los portadores de drogas ilícitas:...

(2011), convertido a pesos colombianos reales de 2010, pues si suponemos que el costo operacional de atender a una persona en el hospital o en la sala de emergencia es más costoso en Estados Unidos que en Colombia, utilizar dichos valores corresponderían a una sobreestimación de los costos. El total del costo en que incurrió el SGSS por hospitalizaciones y urgencias fue de $\$ 333$ mil millones y $\$ 14$ mil millones, respectivamente, para un total aproximado de $\$ 348$ mil millones en 2010 .

\section{Otros}

Finalmente, se incluyen en el análisis los costos de la administración del servicio de salud del SGSS. En este caso, como lo hace el Departamento de Justicia de Estados Unidos (2011), se asume que el costo de administración es equivalente al $6 \%$ de los costos totales de asistencia médica del servicio asociado al consumo de drogas ilícitas. Esta cifra equivale a $\$ 20.957 .523 .001$.

Adicionalmente, incluimos también los gastos del gobierno relacionados con la atención al consumo de drogas ilícitas en los niveles departamental y municipal para el año 2010. Para esto utilizamos la información reportada por las entidades territoriales a través del Formulario Único Territorial (FUT), que muestra una inversión de $\$ 21.512 .560 .417$ a nivel departamental y $\$ 9.566 .562 .394$ a nivel municipal en todo el territorio nacional.

En total, de acuerdo con la metodología que utilizamos, los costos sociales en salud atribuibles al consumo de drogas ilícitas en Colombia suman $\$ 401.328 .695 .830$ para el año 2010 .

\section{B. Costos sociales por pérdidas de productividad laboral}

En esta instancia se estimaron los costos sociales asociados a las pérdidas de productividad por el consumo de drogas ilícitas. Este análisis se fundamenta en la metodología utilizada por el Departamento de Justicia de Estados Unidos (2011), pero se ajustaron los insumos y se corrigieron los valores de productividad en Estados Unidos para aproximarlos al caso colombiano.

Con esta metodología, la medida de productividad se construye a partir de la información de salarios y horas trabajadas de la población, por un lado, 
y de los hábitos de consumo de drogas ilícitas, por otro lado. ${ }^{24}$ Para calcular la pérdida de productividad por consumo de drogas los autores estimaron un modelo por mínimos cuadrados ordinarios para hombres y mujeres, utilizando como variable dependiente la productividad y como variable de interés el consumo de drogas ilícitas (una variable dicótoma). Los resultados sugieren que los hombres que consumen drogas reducen su productividad en un $17 \%$ y las mujeres la reducen en un $18 \%$, y se mantiene todo lo demás constante. En nuestra estimación utilizamos estos resultados.

Para el análisis se calcula el valor de la productividad media del mercado y el valor de la productividad media del hogar, la cual resulta importante cuantificar porque el consumo de drogas ilícitas también afecta el rendimiento en los oficios del hogar, y esto también representa un costo social. Posteriormente, se suman estos dos valores para calcular el valor de la productividad total. Estos datos se calculan por edad y por género, y luego se multiplican por un factor de ajuste, con el fin de obtener una medida bajo un escenario de no consumo de drogas ilícitas. ${ }^{25}$ En nuestra estimación, utilizamos la proporción de usuarios de drogas ilícitas sobre el total de la población, que se calcula a partir de las proyecciones de población del Departamento Administrativo Nacional de Estadística (DANE) y del Estudio Nacional de Consumo de Sustancias Psicoactivas en Colombia, realizado por el Observatorio de Drogas de Colombia en 2013. También se ajustó el valor de la productividad para aproximar los valores estimados por el Departamento de Justicia de Estados Unidos (2011) a los valores de la productividad colombiana. ${ }^{26}$ De esta manera, se obtiene el valor de la productividad ajustada en la fuerza laboral por edad y género, y luego

24 Para esta estimación, el Departamento de Justicia de Estados Unidos (2011) utiliza la Encuesta Nacional en Uso de Drogas y Salud de Estados Unidos (NSDUH) del año 2007 y la Encuesta de Uso del Tiempo en Estados Unidos (ATUS) del año 2010.

25 Este factor equivale a $1 /(1-a b)$, donde $a$ es la proporción de consumidores de drogas por edad y por género, y $b$ es la reducción en productividad descrita anteriormente, atribuible a hombres y mujeres.

26 Para esta aproximación multiplicamos el valor de la productividad por la relación entre el valor del PIB en Colombia con el de Estados Unidos, lo ajustamos por la inflación para Estados Unidos y lo multiplicamos por la tasa de cambio promedio de 2010. Para mayores detalles, ver Departamento de Justicia de Estados Unidos (2011). 
Gutiérrez y Tobón: El gasto fiscal de la guerra contra los portadores de drogas ilícitas:...

se computa un promedio ponderado para tener un valor promedio de la proporción de consumidores de drogas ilícitas y la productividad por género. En particular, estimamos que la proporción de usuarios de drogas ilícitas de género masculino es 0,058 , y la de género femenino es de 0,036 sobre el total de la población. Además, la productividad anual promedio para una persona de género masculino se estima en $\$ 22.641 .760$, y para una persona de género femenino en $\$ 18.325 .428$.

Una vez establecido el valor de la productividad ajustada para el total de la población por género y el costo de la productividad promedio anual, se estiman las pérdidas de productividad en el mercado laboral, asociadas al consumo en 2010. Para esto, multiplicamos el valor de la productividad promedio, por el número de usuarios y por la pérdida de productividad asociada al consumo. Los resultados se presentan en la Tabla 3.

Tabla 3. Costos atribuibles al consumo de drogas ilícitas por pérdidas de productividad en el mercado laboral

\begin{tabular}{lcccccc}
\hline & Población & $\begin{array}{c}\text { Proporción de } \\
\text { usuarios }\end{array}$ & $\begin{array}{l}\text { Número de } \\
\text { usuarios }\end{array}$ & $\begin{array}{c}\text { Productividad } \\
\text { ajustada }\end{array}$ & $\begin{array}{c}\text { Reducción en } \\
\text { productividad }\end{array}$ & $\begin{array}{c}\text { Productividad } \\
\text { pérdida total }\end{array}$ \\
\hline Hombres & 22.466 .660 & 0,058 & 1.298 .617 & $\$ 22.641 .760$ & $17 \%$ & $\$ 4.998 .506 .788 .808$ \\
Mujeres & 23.042 .924 & 0,036 & 823.309 & $\$ 18.325 .428$ & $18 \%$ & $\$ 2.715 .749 .171 .274$ \\
Total & 45.509 .584 & - & 2.121 .927 & - & - & $\$ 7.714 .255 .960 .082$ \\
\hline
\end{tabular}

Fuente: construcción propia con base en la información del DANE y la Encuesta Nacional de Consumo de Sustancias Psicoactivas en Colombia, así como en el Departamento de Justicia de Estados Unidos (2011). Precios de 2010.

\section{Crimen}

El tercer componente de la estimación de los costos sociales del consumo de drogas ilícitas es el correspondiente al crimen, con el cual se relaciona de distintas formas. Goldstein (1995) propone tres canales: a través de los efectos psicofarmacológicos en el usuario (vía intoxicación), a través del financiamiento del consumo (en lo que se denomina crimen económico) y a través de la operación de los mercados y la distribución de la droga o el crimen sistémico. Un asunto complejo es la relación causal entre el consumo y el crimen, pues no es claro si el consumo de drogas causa el crimen, si 
el crimen fomenta el consumo o si ambos son una consecuencia de otros factores sociales y económicos. En este apartado se propone una forma de cuantificar los costos sociales del crimen derivado del consumo de drogas siguiendo lo realizado por el Departamento de Justicia de Estados Unidos (2011); en consecuencia, el supuesto que se realiza es que la proporción del crimen atribuido al consumo de drogas es el mismo en Colombia y Estados Unidos. Este supuesto es controvertible, pero para esta investigación no se contó con la información que permitiera distinguir el caso colombiano.

Los costos sociales asociados al crimen por consumo de drogas ilícitas recaen, principalmente, sobre las víctimas. Estas pérdidas se pueden estimar a partir de los perjuicios tangibles, en particular los gastos médicos de atención a las víctimas, las pérdidas de propiedad y los costos en productividad por días de incapacidad de las víctimas de crímenes relacionados con el consumo de drogas.

Para abordar estos costos se estima primero el número total de víctimas de crímenes violentos y crímenes a la propiedad reportados en el año 2010. Para esto, se tomaron el número de denuncias presentadas en los sistemas de información de la Policía Nacional y se dividieron en dos categorías: crimen violento y crimen a la propiedad. En la categoría de crimen violento se incluyeron homicidios, delitos sexuales y casos de lesiones personales, y en la de crimen a la propiedad se incluyeron el hurto a personas, motos y carros. Esta agregación es similar a la que realiza el Departamento de Justicia de Estados Unidos (2011), cuyos supuestos fueron el soporte para hacer la estimación. Como la información disponible corresponde a las denuncias y no a la ocurrencia de los delitos, se corrigió la cifra total de casos por la tasa de denuncia. ${ }^{27}$ Una vez consolidado el número de víctimas para cada tipo de crimen, se utilizaron, por evento, los costos médicos, el valor de las pérdidas materiales, los costos asociados a pérdidas de productividad y, por último, el factor de atribución al consumo de drogas ilícitas según el tipo de crimen. Los valores y los factores de atribución supuestos se tomaron del Departamento de Justicia de Estados Unidos (2011), ajustándolos a pesos reales de 2010. Si

27 La tasa de denuncia utilizada es del $25 \%$, estimada en la Encuesta de Convivencia y Seguridad Ciudadana de 2012 del DANE. Esta corrección se aplica a los delitos diferentes a homicidios, para los que se supone una tasa de denuncia del $100 \%$. 
Gutiérrez y Tobón: El gasto fiscal de la guerra contra los portadores de drogas ilícitas:...

se considera que, ante la incertidumbre, el interés es sobrestimar los costos, es consecuente tomar los valores por evento para Estados Unidos, donde tanto la atención en salud, como el ingreso per cápita y la productividad son mayores.

Tabla 4. Costos relacionados con la ocurrencia de crimenes asociados al consumo de drogas ilícitas

\begin{tabular}{|c|c|c|c|}
\hline & Crimen violento & Crimen a la propiedad & Total \\
\hline Número de eventos & 252.398 & 331.024 & 583.422 \\
\hline \multicolumn{4}{|l|}{ A. Costos médicos } \\
\hline Costo por evento & $\$ 76.346$ & $\$ 0$ & - \\
\hline Subtotal & $\$ 19.269 .558 .223$ & $\$ 0$ & $\$ 19.269 .558 .223$ \\
\hline \multicolumn{4}{|l|}{ B. Costos en pérdida de propiedad } \\
\hline Valor propiedad por evento & $\$ 236.519$ & $\$ 1.522 .096$ & - \\
\hline Tasa de daño & $11 \%$ & $26 \%$ & - \\
\hline Pérdida por evento & $\$ 26.017$ & $\$ 395.745$ & - \\
\hline Subtotal & $\$ 6.566 .649 .477$ & $\$ 131.001 .063 .183$ & $\$ 137.567 .712 .660$ \\
\hline \multicolumn{4}{|c|}{ C. Costos en pérdidas de productividad } \\
\hline Costo por evento (mercado) & $\$ 51.226$ & $\$ 9.497$ & - \\
\hline Costo por evento (hogar) & $\$ 13.475$ & $\$ 3.920$ & - \\
\hline Subtotal & $\$ 16.330 .402 .998$ & $\$ 4.441 .349 .008$ & $\$ 20.771 .752 .006$ \\
\hline \multicolumn{4}{|l|}{ D. Costos totales crimen } \\
\hline Total & $\$ 42.166 .610 .698$ & $\$ 135.442 .412 .191$ & $\$ 177.609 .022 .889$ \\
\hline Factor atribución & $12 \%$ & $31 \%$ & - \\
\hline Total atribuido al uso de drogas & $\$ 5.018 .937 .668$ & $\$ 41.983 .504 .827$ & $\$ 47.002 .442 .495$ \\
\hline
\end{tabular}

Fuente: construcción propia con base en la información del DANE y la Policía Nacional de Colombia, así como en Departamento de Justicia de Estados Unidos (2011). Precios de 2010.

Los supuestos son los siguientes. Para los costos médicos promedio por asistencia médica para crímenes violentos $\$ 76.346$. Para el valor de la propiedad perdida promedio por cada crimen violento $\$ 236.519$ con una tasa de daño del $11 \%$, y por cada crimen a la propiedad $\$ 1.522 .096$ con 
una tasa de daño del $26 \%$. Para las pérdidas de productividad por crímenes violentos, $\$ 51.226$ por evento en el mercado laboral y $\$ 13.475$ en el hogar. Para las pérdidas de productividad por crímenes a la propiedad, $\$ 9.497$ por evento en el mercado laboral y $\$ 3.920$ en el hogar. Finalmente, suponemos un factor de atribución del 12\% sobre el total de crímenes violentos y del $31 \%$ sobre el total de crímenes a la propiedad, al consumo de drogas ilícitas (véase Tabla 4). ${ }^{28}$

\section{Discusión}

Nuestra estimación indica que la persecución al delito de porte, fabricación y tráfico de estupefacientes en el sistema de justicia criminal colombiano ha tenido un costo aproximado de, al menos, $\$ 10,6$ billones entre 2001 y 2015. En los últimos cinco años el costo promedio anual fue de alrededor de $\$ 893.000$ millones y en 2015 el costo fue de $\$ 812.000$ millones. Las justificaciones para semejante esfuerzo fiscal pueden ser diversas; por ejemplo, al gobierno le interesa evitar el tráfico de estupefacientes, ya que Colombia es el principal exportador de cocaína a Estados Unidos y Europa y, por eso, parte del esfuerzo se concentra en prevenir el tráfico internacional de drogas. No obstante, encontramos tres argumentos que indican que, en la generalidad, no parece aplicar ninguno de estos casos.

Primero, a pesar de que la legislación y la jurisprudencia vigentes en Colombia protegen a los consumidores y, en particular, a quienes han sido portadores de cantidades menores a la dosis mínima o que portan dosis mayores para su aprovisionamiento, estos límites no son claros y están sujetos a la arbitraria interpretación de policías, jueces y fiscales. En las encuestas aplicadas a 96 oficiales de la policía antes de la decisión de la Corte de flexibilizar la interpretación de las dosis mínimas, se encontró que más del $40 \%$ no conocían las cantidades mínimas establecidas. Además, quienes respondieron la pregunta conocían el mínimo permitido para el porte de marihuana, pero son muy pocos los que lo sabían para las demás drogas como la cocaína, la heroína y el bazuco, siendo esta última una de las drogas ilícitas

28 Para mayores detalles sobre la construcción de estos supuestos, véase Departamento de Justicia de Estados Unidos (2011). 
Gutiérrez y Tobón: El gasto fiscal de la guerra contra los portadores de drogas ilícitas:...

más consumidas en ciudades como Bogotá o Medellín. De hecho, menos del $10 \%$ de las personas encuestadas conocían las cantidades mínimas para al menos tres tipos de droga diferentes.

Segundo, las capturas por el delito de porte, fabricación y tráfico de estupefacientes son en su mayoría por drogas diferentes a la cocaína, y corresponden a consumo interno y tráfico asociado a consumo interno. De acuerdo con la información de SIEDCO, entre las capturas realizadas entre 2010 y 2014 a nivel nacional, el 53 \% correspondió a capturas por marihuana, el $23 \%$ a basuco y el resto se asocia a cocaína, base de coca y otras drogas. Cabe resaltar que la marihuana y el basuco son drogas para el mercado interno.

Tercero, según la información del SIEDCO, cuando se realizan capturas las cantidades de droga incautada son generalmente bajas. La distribución de las cantidades de marihuana incautadas en las capturas por el consumo de esta sustancia entre 2010 y 2014 se presenta en la Figura 4. En el 6\% de los casos la cantidad incautada es igual o menor a 20 gramos, correspondiente a la dosis mínima; el $77 \%$ de los casos es igual o menor a 100 gramos, y el $90 \%$ es menor o igual a 200 gramos. Como se observa, la distribución se concentra alrededor de la cantidad definida como dosis mínima.

Figura 4. Distribución de la cantidad de marihuana incautadas en capturas realizadas entre 2010 y 2014

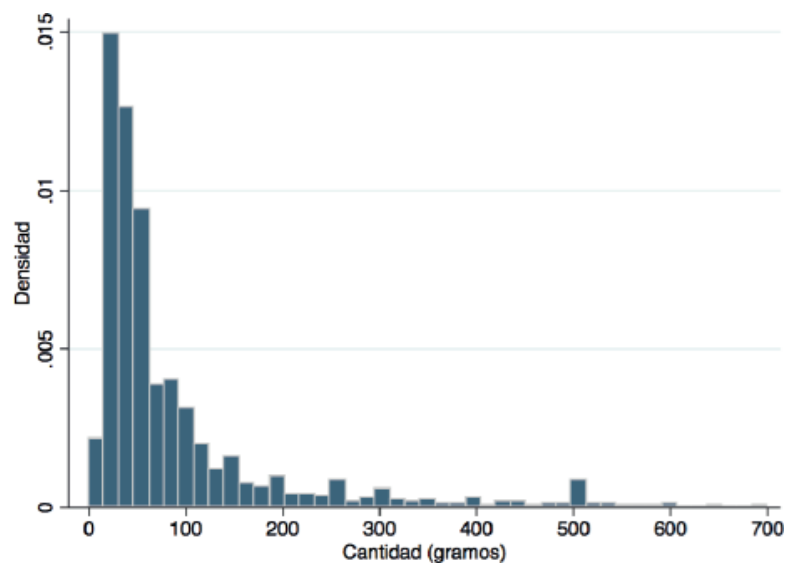

Fuente: construcción propia a partir de datos de SIEDCO de la Policía Nacional de Colombia. 
La situación es similar para la cocaína, para la cual en el $10 \%$ de los casos la cantidad incautada es igual o menor a 2 gramos, en el $50 \%$ es igual o menor a 10 gramos y en el $75 \%$ de los casos es igual o menor a 30 gramos. Teniendo en cuenta la variación en las calidades, estas cantidades incautadas de marihuana y cocaína pueden corresponder a dosis de aprovisionamiento para el consumo en un período largo de tiempo.

Otra posible razón para realizar estos esfuerzos fiscales corresponde al interés por evitar la violencia y el crimen asociados al consumo de drogas ilícitas. En la sección III se estimaron estos costos para 2010, los cuales se presentan en la Tabla 5 con precios de 2016. De acuerdo con nuestra estimación, los costos por el crimen y la violencia que se derivan del consumo de drogas ilícitas en Colombia suman alrededor del $7 \%$ del gasto fiscal anual por la persecución del delito de porte, fabricación y tráfico de estupefacientes. ${ }^{29}$ En esta medida, y sujeto a los supuestos sobre los que se construyeron ambas estimaciones, resulta desproporcionado el gasto fiscal en la persecución del crimen, con relación al costo social y la violencia asociados al consumo de estupefacientes en Colombia. Como estimación del gasto fiscal en la persecución del delito se fundamenta aquí en el costo esperado de la captura, la hipótesis que se sostiene es que esta situación puede derivarse de los esquemas de incentivos definidos en la policía. En particular, y aunque las entrevistas con oficiales permiten ver que hay un esfuerzo interno por evitar los incentivos basados en resultados operacionales, la cultura organizacional en la policía aún valora los resultados positivos en capturas e incautaciones. Esto puede generar incentivos perversos al interior de la policía, que falsamente relacionan las capturas de consumidores con una amenaza real a la seguridad ciudadana, por el hecho mismo del consumo.

Finalmente, puede ser que el gobierno busque disuadir a los consumidores mediante la persecución del delito de porte, fabricación y tráfico de estupefacientes, independientemente de las problemáticas de tráfico internacional o violencia y crimen, asociadas al consumo. Como discutimos en la sección III, el consumo implica otro tipo de costos, entre los cuales se

29 Esto representa el 6,5\% sobre el costo promedio anual para los últimos 5 años (derivados de las capturas por el delito de porte, fabricación y tráfico de estupefaciente) y el 6,9\% relativo a los costos de 2010 (derivados de las capturas). 
Gutiérrez y Tobón: El gasto fiscal de la guerra contra los portadores de drogas ilícitas:...

encuentran, adicional a los costos del crimen asociado al consumo, los costos asociados al gasto fiscal en el sistema de salud y las pérdidas de productividad laboral. La Tabla 6 presenta las cifras en precios de 2016, para hacerlas comparables a nuestra estimación de costos en el sistema de justicia criminal derivado de las capturas.

Tabla 5. Costos sociales por el crimen asociado al consumo de drogas ilícitas en Colombia para el año 2010

\begin{tabular}{lcc}
\hline & Precios 2010 & Precios 2016 \\
\hline Crimen violento & $\$ 5.018 .937 .668$ & $\$ 6.207 .893 .486$ \\
Crimen a la propiedad & $\$ 41.983 .504 .827$ & $\$ 51.929 .141 .858$ \\
Subtotal crimen & $\$ 47.002 .442 .495$ & $\$ 58.137 .035 .344$ \\
\hline
\end{tabular}

Fuente: construcción propia con base en la información del DANE y la Policía Nacional de Colombia, así como en Departamento de Justicia de Estados Unidos (2011). Precios de 2010.

Tabla 6. Costos en salud, pérdidas de productividad laboral y crimen asociado al consumo de drogas ilícitas en Colombia, 2010

\begin{tabular}{lcc}
\hline & Precios 2010 & Precios 2016 \\
\hline A. Costos en salud & & \\
\hline Tratamiento especializado & $\$ 1.781 .705 .920$ & $\$ 2.203 .781 .220$ \\
Hospitalizaciones y sala de emergencia & $\$ 347.510 .344 .098$ & $\$ 429.833 .431 .731$ \\
Otros salud & $\$ 52.036 .645 .812$ & $\$ 64.363 .810 .819$ \\
Subtotal salud & $\$ 401.328 .695 .830$ & $\$ 496.401 .023 .769$ \\
\hline B. Costos por pérdidas de productividad laboral & $\$ 4.998 .506 .788 .808$ & $\$ 6.182 .622 .655 .848$ \\
\hline Hombres & $\$ 2.715 .749 .171 .274$ & $\$ 3.359 .093 .638 .027$ \\
Mujeres & $\$ 7.714 .255 .960 .082$ & $\$ 9.541 .716 .293 .875$ \\
\hline Subtotal productividad
\end{tabular}

Fuente: construcción propia con base en la información del DANE y la Policía Nacional de Colombia, así como en Departamento de Justicia de Estados Unidos (2011). Precios de 2010. 
Si bien, como se señaló antes, este listado no es exhaustivo, varios elementos pueden analizarse de estas cifras. Por una parte, es desproporcionadamente mayor el costo social por las pérdidas de productividad laboral que por la atención en el sistema de salud; incluso, ante la ausencia de otros costos que no estimamos, las pérdidas de productividad son suficientemente altas (superiores al $1 \%$ del producto interno bruto) y parecieran ser el costo social más importante derivado del consumo de drogas ilícitas. De hecho, el costo social por las pérdidas de productividad laboral es más de diez veces el gasto fiscal en la persecución del delito. Si la justificación para el gasto actual en el sistema de justicia criminal fuera la disuasión de los consumidores, lo racional sería elevar este gasto hasta, por lo menos, $\$ 10$ billones, equivalentes a la suma de los costos en salud y las pérdidas de productividad. Semejante situación es impensable y hace poco factible seguir este enfoque.

\section{Agradecimientos}

Por la asistencia en investigación, le agradecemos a Luisa Cardona y María Paulina Domínguez. Por los comentarios iniciales, le agradecemos a Daniel Mejía. Por la retroalimentación y el apoyo en el suministro de información, le agradecemos a la Fiscalía General de la Nación, en particular al Exdirector de Políticas y Estrategia, Miguel La Rota y Sebastián Sierra; a la Policía Nacional, el Ministerio de Justicia y del Derecho y al Instituto Nacional Penitenciario y Carcelario (INPEC). Por la financiación, le agradecemos al Centro de Estudios en Seguridad y Drogas (CESED) de la Universidad de los Andes y a Open Society Foundations.

\section{Referencias}

Anderson, D. M., Hansen, B. \& Rees, D. (2013). Medical Marijuana Laws, Traffic Fatalities, and Alcohol Consumption. Journal of Law and Economics, 56(2), 333-369.

Anderson, D. M., Hansen, B. \& Rees, D. (2015). Medical Marijuana Laws and Teen Marijuana Use. American Law and Economics Review, 17(2), $495-528$. 
Gutiérrez y Tobón: El gasto fiscal de la guerra contra los portadores de drogas ilícitas:...

Anderson D. M, Rees, D. (2014) The legalization of recreational marijuana: how likely is the worst-case scenario? Journal of Policy Analysis and Management, 33, 221-232.

Aparicio Barrera, J. (2009). Criminalidad en cifras: delitos en Colombia, 2008. Revista Criminalidad, 51(1), 17-23.

Barco-Pérez, J. \& Arana-Cosme, J. (2014). Resultados operativos de la Policía Nacional, 2013. Revista Criminalidad, 56(2), 141-145.

Buitrago, J., Bernal, P. \& Rodríguez, J. (2015). Registros administrativos de policía para la consolidación de cifras de criminalidad en Colombia. Revista Criminalidad, 57(2), 11-22.

Buitrago, J. \& Norza-Céspedes, E. (2016). Registros de la criminalidad en Colombia y actividad operativa de la Policía Nacional durante el año 2015. Revista Criminalidad, 58(2), 9-20.

Cortés, A. (2011). Análisis del sistema de defensoría pública en Colombia. Nuevos Paradigmas de las Ciencias Sociales Latinoamericanas, 2(3), 87-118.

Departamento de Justicia de Estados Unidos (2011). The Economic Impact of Illicit Drug Use on American Society. Washington, D.C.: U.S. Department of Justice, National Drug Intelligence Center.

Duarte-Velásquez, Y. (2013). Resultados operativos de la Policía Nacional, 2012. Revista Criminalidad, 55(3), 151-156.

Espino-Duque, G. (2010). Resultados operacionales y servicios de la Policía Nacional, 2009. Revista Criminalidad, 52(1), 143-148.

Goldstein, P. (1995). Drugs and Violence: Myth and Reality. En L. Joseph (Ed.), Crime, Communities and Public Policy (pp. 181-200). Chicago: University of Chicago Center for Urban Research and Policy Studies.

Hall, W. \& Lynskey, M. (2016). Evaluating the public health impacts of legalizing recreational cannabis use in the United States. Addiction, 111(10), 1764-1773. 
Harwood, H. J., Fountain, D. \& Livermore, G. (1998). The Economic Costs of Alcohol and Drug Abuse in the United States1992. Rockville, MD: National Institutes on Drug Abuse. Recuperado de: https://archives.drugabuse.gov/publications/economic-costsalcohol-drug-abuse-in-united-states-1992

Harwood, H. J., Fountain, D. \& Livermore, G. (1999). A report and commentaries: Cost estimates for alcohol and drug abuse. Addiction, 94(5), 631-647.

Harwood, H. J., Kallinis, S. \& Liu, C. (2001). The Cost and Components of Substance Abuse Treatment. Rockville, MD: Center for Substance Abuse and Mental Health Services Administration, Department of Health and Human Services.

Harwood, H. J., Napolitano, D. M., Kristiansen, P. L. \& Collins, J. L. (1984). Economic Costs to Society of Alcohol and Drug Abuse and Mental Illness: 1980. (Report No. RTI/2734/00-01FR) Recuperado de: https://www.ncjrs.gov/pdffiles1/Digitization/117820NCJRS.pdf

MacCoun, R., Pacula, R., Chriqui, J. Harris, K. \& Reuter, P. (2009). Do Citizens Know Whether Their State Has Decriminalized Marijuana? Assessing the Perceptual Component of Deterrence Theory. Review of Law and Economics, 5(1), 347-371.

Ministerio de Justicia y del Derecho (2013). Análisis del ciclo criminal en el delito de tráfico, fabricación o porte de estupefacientes 2008-2012. Bogotá D.C.: Ministerio de Justicia y del Derecho, Viceministerio de Política Criminal y Justicia Restaurativa.

Norza-Céspedes, E. \& Espino-Duque, G. (2011). Resultados operacionales de la Policía Nacional, 2010. Revista Criminalidad, 53(1), 151-163.

Norza-Céspedes, E. \& López-Guaje, W. (2012). Resultados de la Policía Nacional en la lucha contra el crimen, 2011. Revista Criminalidad, 54(1), 161-169. 
Gutiérrez y Tobón: El gasto fiscal de la guerra contra los portadores de drogas ilícitas:...

Office of National Drug Control Policy (ONDCP) (2001). The Economic Costs of Drug Abuse in the United States, 1992-1998. Recuperado de: https://www.hsdl.org/?view\&did=3443

Office of National Drug Control Policy (ONDCP) (2004). The Economic Costs of Drug Abuse in the United States, 1992-2002. Recuperado de: https://www.hsdl.org/?abstract\&did=454919

Rodríguez, J. F. (2008). Resultados operativos de la Policía Nacional de Colombia 1959-2007: Un efectivo mecanismo de control social del Estado. Revista Criminalidad, 50(1), 435-440. 